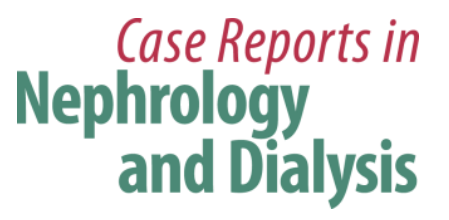

\title{
Delayed Admission and Management of Pediatric Acute Kidney Injury and Multiple Organ Dysfunction Syndrome in Children with Multiple Wasp Stings: A Case Series
}

\author{
Cahyani Gita Ambarsari ${ }^{\mathrm{a}}$ Risti Maulani Sindih ${ }^{\mathrm{a}}$ Meilania Saraswati ${ }^{\mathrm{b}}$ \\ Partini Pudjiastuti Trihono ${ }^{a}$ \\ aDepartment of Child Health, Cipto Mangunkusumo Hospital, Faculty of Medicine \\ Universitas Indonesia, Jakarta, Indonesia; ${ }^{b}$ Department of Pathology Anatomy, Cipto \\ Mangunkusumo Hospital, Faculty of Medicine Universitas Indonesia, Jakarta, Indonesia
}

\section{Keywords}

Acute kidney injury $\cdot$ Hemolysis $\cdot$ Plasma exchange $\cdot$ Renal dialysis · Wasp sting

\begin{abstract}
Multiple wasp stings may cause fatal complications, such as anaphylactic reactions, intravascular hemolysis, rhabdomyolysis, acute kidney injury (AKI), increased levels of liver enzymes, clotting abnormalities, or even death. AKI-related mortality due to multiple wasp stings may reach $25 \%$, occurring within the early onset of disease; therefore, renal function should be continuously monitored within the first few days following the stings. Herein, we report 2 cases of AKI due to multiple stings of wasp (Vespa affinis). In both cases, delayed hospital admissions
\end{abstract}




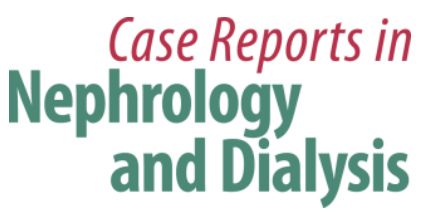

\begin{tabular}{l|l} 
Case Rep Nephrol Dial 2019;9:137-148 \\
\hline DOI: 10.1159/000504043 & $\begin{array}{l}\text { @ } 2019 \text { The Author(s). Published by S. Karger AG, Basel } \\
\text { www.karger.com/cnd }\end{array}$ \\
\hline
\end{tabular}

and gradual loss of kidney function along with hemolysis and anemia without rhabdomyolysis were observed. Diuresis was reduced on the 10th day following the stings in the first case, whereas it occurred on the 5th day in the second case. Both cases had biopsy results of acute tubular injury and acute interstitial nephritis. The first case improved with intermittent hemodialysis, whereas the second required continuous renal replacement therapy and plasma exchange because hemolysis was more severe, which was presumably caused by a greater number of stings and larger amount of toxins involved. Multiple organ dysfunction syndrome was also observed in the second case; hence, high-dose steroid therapy was administered to alleviate interstitial fibrosis. Both cases showed that although AKI occurring after multiple wasp stings usually have fatal consequences. Administering fluid treatment and steroid therapy and selecting accurate renal replacement therapy modalities during the few first days after the stings may result in favorable long-term outcomes.

(C) 2019 The Author(s)

Published by S. Karger AG, Basel

\section{Introduction}

Insect bites, particularly by members of the Hymenoptera family, such as bees, wasps, flies, and ants, are commonly reported [1]. In particular with wasps, the incidence of wasp stings in developed countries has been known to usually involve a single sting; therefore, symptoms may include anaphylactic reaction [2]. On the contrary, wasp stings in developing countries may involve a colony of wasps that may cause hemolysis and rhabdomyolysis that therefore cause acute kidney injury (AKI) [3].

Although AKI does not always occur following wasp stings, with a report in China showing only $21 \%$ of all cases of stings, the mortality rate due to AKI following multiple wasp stings is relatively high, reaching $25 \%$ with death occurring at the early onset of disease [3]. Approximately $11 \%$ of the AKI cases following wasp stings require one or more renal replacement therapy (RRT) modalities [4-6]. Progressive kidney dysfunction may occur very rapidly, which results in multiple organ dysfunction syndrome (MODS) [5].

This case series reports 2 cases of AKI following multiple wasp stings in Indonesia with delayed hospital admission; in addition, one of them suffered from rare complications of MODS involving the kidney, pancreas, eyes, and liver. The intensive dialysis and steroid therapy resulted in successful recovery of kidney function and other involved organ functions in both cases. Moreover, in the long-term monitoring evaluation, the kidney function of both patients returned to normal.

\section{Case Presentations}

Case 1

A 15-year-old male patient came to Cipto Mangunkusumo Hospital (CMH), a tertiary referral hospital, with complaints of vomiting, headache, and swollen eyelids after he was stung by wasps (Vespa affinis) 10 days before admission. The patient was walking home from school across a garden when a group of children was hiding and knocking over a wasp nest located above him. He was then attacked by a swarm of wasps, which stung him over his scalp and 


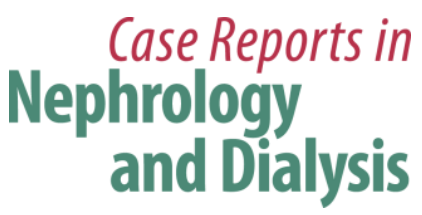
\begin{tabular}{l|l} 
Case Rep Nephrol Dial 2019;9:137-148 \\
\hline DOI: 10.1159/000504043 & $\begin{array}{l}\text { (c) 2019 The Author(s). Published by S. Karger AG, Basel } \\
\text { www.karger.com/cnd }\end{array}$ \\
\hline
\end{tabular}

Ambarsari et al.: Critical Cases of Pediatric AKI following Multiple Wasp Stings

extremities. Within $12 \mathrm{~h}$ after the attack, he experienced vomiting and swollen eyes. Several days later, the vomiting worsened, and shivering and shortness of breath occurred. Therefore, the patient was then hospitalized in a local hospital where he received intravenous (IV) fluids, 3 doses of $5 \mathrm{mg}$ IV dexamethasone, IV ranitidine, IV ceftriaxone, and oral paracetamol. The patient was subsequently referred to $\mathrm{CMH} 10$ days after the attack as he had reduced diuresis with a blood urea nitrogen (BUN) level of $42.7 \mathrm{mmol} / \mathrm{L}$ and creatinine level of 1,971.3 $\mu \mathrm{mol} / \mathrm{L}$. His blood pressure was $160 / 130 \mathrm{~mm} \mathrm{Hg}$, pulse rate was 120 beats/min, and respiratory rate was 28 times/min. He was pale with swollen eyelids and 30 wasp sting marks over his scalp, both arms, and lower extremities (Fig. $1 \mathrm{a}-\mathrm{c}$ ). His diuresis rate was $0.6 \mathrm{~mL} / \mathrm{kgBW} / \mathrm{h}$. Laboratory examination results are presented in Table 1 , and renal ultrasonography revealed normal results.

He was administered IV fluids, sublingual nifedipine, IV furosemide, oral amlodipine, and packed red cell transfusion. He also underwent intermittent hemodialysis (HD) and the first renal biopsy (Fig. 2a, b). After 7 sessions of HD, his kidney function improved, with BUN 7.3 $\mathrm{mmol} / \mathrm{L}$ and eGFR $74 \mathrm{~mL} / \mathrm{min} / \mathrm{m}^{2}$ (Fig. 3a). The patient then underwent another biopsy at the 12th week after the wasp sting, which showed slight improvement although chronic features were already found (Fig. 2c, d). His kidney function returned to normal within 14 weeks after being stung, with BUN of $4.5 \mathrm{mmol} / \mathrm{L}$, serum creatinine of $61.9 \mu \mathrm{mol} / \mathrm{L}$, and normal urinalysis results. Follow-up evaluation was performed at the outpatient clinic for 48 months and revealed that the kidney function remained normal (Fig. 3a, b).

Case 2

A 12-year-old girl came to CMH with worsening swelling all over her body after being stung by wasps (Vespa affinis) 12 days before admission. The patient was cleaning her house roof when she accidentally hit a wasp nest. Multiple sting lesions were found over her body, which were itchy with burning pain. The patient sought treatment from a general practitioner, and her symptoms temporarily subsided; however, she developed nausea and vomiting 5 days later. Her urine production drastically decreased; therefore, she was admitted to a local hospital and received IV fluids. She had worsening swelling all over her body, which was accompanied with shortness of breath.

She was referred to $\mathrm{CMH}$ due to sudden onset of black vision and anuria. Her blood pressure was 130/88 mm Hg, pulse rate was 98 beats/min, and respiratory rate 28 times/min. Her face and extremities were edematous, and 80 wasp sting marks were found over her back, left arm, and both lower extremities (Fig. 1b, c). Eye examination revealed no light perception. Laboratory examination results showed BUN of $85.2 \mathrm{mmol} / \mathrm{L}$ and a creatinine level of 1,068.5 $\mu \mathrm{mol} / \mathrm{L}$. Acute pancreatitis (amylase $3.37 \mu \mathrm{kat} / \mathrm{L}$, lipase $5.96 \mu \mathrm{kat} / \mathrm{L}$ ) and liver dysfunction (aspartate aminotransferase [AST] $1.4 \mu \mathrm{kat} / \mathrm{L}$, alanine transferase [ALT] $3.17 \mu \mathrm{kat} / \mathrm{L}$ ) were also observed (Table 1). Abdominal ultrasonography revealed normal abdomen.

She was treated with IV glucose and fluids, oral amlodipine and carvedilol, IV ondansetron, IV omeprazole, packed red cell transfusion, and continuous venovenous hemodiafiltration (CVVHDF). The patient started to regain her vision with visual acuity of $3 / 60$ for both eyes after $12 \mathrm{~h}$ of CVVHDF, and she finally regained her normal vision with visual acuity of $6 / 6$ for both eyes after $24 \mathrm{~h}$ of CVVHDF. After $92 \mathrm{~h}$ of CVVHDF, her swelling was getting better, and the ureum level temporarily improved. Nevertheless, since she still had a high lactate dehydrogenase (LDH) level at $13.7 \mu \mathrm{kat} / \mathrm{L}$, which indicated an ongoing hemolysis as well as 


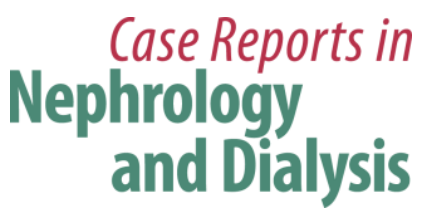

Case Rep Nephrol Dial 2019;9:137-148

DOI: 10.1159/000504043

(c) 2019 The Author(s). Published by S. Karger AG, Base www.karger.com/cnd

Ambarsari et al.: Critical Cases of Pediatric AKI following Multiple Wasp Stings

continuously increased ureum level of $>5 \mathrm{mmol} / \mathrm{L} /$ day, CVVHDF was continued with 2 sessions of plasma exchange (PE) with a 24 -h interval between sessions. The calculated plasma volume for the PE sessions was $2 \mathrm{~L}$ and was removed and replaced with $3 \mathrm{~L}$ of $5 \%$ albumin in each session. Pancreatitis and liver dysfunction improved after 2 sessions of PE (Table 2). Renal biopsy showed features similar to those in Case 1 (Fig. 2e-g).

Methylprednisolone (MP) pulse was administered for 3 consecutive days at the dose of $1 \mathrm{~g} /$ day (body weight, $34 \mathrm{~kg}$ ) because an active hemolysis was suspected based on low hemoglobin levels (Table 2). Oral MP pulse was continued for a month; the treatment was continued with a second dose of MP pulse and subsequently tapered off of the oral MP for the next month.

Her blood pressure was normalized within 4 weeks after the wasp stings, and the kidney function returned to normal within 10 weeks after the wasp stings with BUN of $3.2 \mathrm{mmol} / \mathrm{L}$ and creatinine level of $44.2 \mu \mathrm{mol} / \mathrm{L}$ (Table 2). A second biopsy was performed at the 10 th week after the wasp stings due to persistent proteinuria (Fig. 2h). Follow-up evaluation was performed for 48 months and revealed that the kidney function returned to normal (Fig. 3c, d).

\section{Discussion and Conclusion}

Typical clinical symptoms occurring after wasp stings can vary depending on the number of stings, venom strength, and patient's immunity. Renal failure or death usually occurs after 20-200 wasp stings [7-11]. In the first case, the patient only had AKI as a complication after obtaining 30 stings, whereas in the second case, the patient also experienced MODS in addition to AKI after obtaining 80 stings. These differences are assumed to be caused by different numbers of sting marks and different immune responses between the 2 patients. Moreover, the first patient received IV fluid and steroid treatment within the first couple of days after the stings [8, 12].

Renal complication does not occur as rapidly as anaphylactic reaction; therefore, wasp sting cases, particularly those with a large number of stings, should be monitored within the next few days to observe probable kidney dysfunction by closely monitoring the blood pressure, diuresis, urinalysis, ureum, and creatinine serum levels. Liver dysfunction, coagulation abnormalities, rhabdomyolysis, or hemolysis may occur within 1-3 days following the stings, and renal damage may gradually develop within the next 4-9 days. Reduced diuresis may occur within 1-9 days after the stings $[6,8,9,12]$. Delayed onset of AKI due to wasp stings was found in the first case, in which the patient had oliguria on the 10th day after the stings, whereas reduced diuresis occurred earlier in the second case; i.e., on the 5th day, and anuria occurred on the 13th day [9].

In the first case of this case report, the observed effects of wasp venom were hemolysis and AKI without other organ abnormalities. Anaphylaxis was not observed, but the effects of wasp venom were suspected to occur due to hypersensitivity to multiple wasp stings based on a significant increase of IgE (1,578 ng/L) (Table 1). In the second case, hemolysis and AKI without rhabdomyolysis were observed. The probability of rhabdomyolysis was excluded due to negative results of myoglobin levels in the blood, whereas the urinary myoglobin level was not examined because this test is not available in Indonesia. Anaphylaxis did not occur in both 


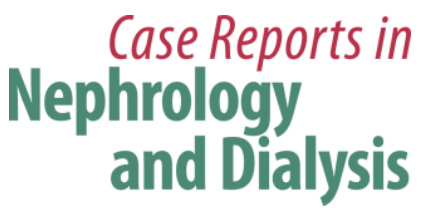

Case Rep Nephrol Dial 2019;9:137-148

cases. The normal IgE level indicates that hypersensitivity reaction might not have occurred in the second case (Table 1) [8, 9].

In addition to kidney complications, the second patient also experienced pancreatic, eye, and liver complications, which were diagnosed on the 13th day only (Fig. 3c). A case of AKI accompanied with pancreatitis was reported in Korea after a patient was stung by $>40$ wasps. Pancreatitis was resolved within 6 days after the stings after a 3-day CRRT [13]. Cases of optic neuritis that have been reported always involved a direct periorbital wasp sting including the eyelids and conjunctiva or even a direct sting on the cornea [14-16]. The patient in the second case did not experience direct stings on her eyes or periorbital region, but optic neuritis was probably caused by a large amount of venom caused by multiple wasp stings that penetrate into vascularization. Nephrotoxicity of the wasp venom may occur due to the heme protein, phosphate, and uric acid, which are produced during the rhabdomyolysis and hemolysis processes. Rhabdomyolysis and hemolysis are causal factors of renal ischemia and damage [2]. Both patients in our case report experienced anemia and their peripheral blood test showed anisopoikilocytosis with burr and pencil cells. During the monitoring phase, the hemoglobin level was reduced, which was accompanied by increased CK and LDH levels. It also indicates ongoing hemolysis $[5,6,9]$. Both cases in our report also showed hyperphosphatemia and hyperuricemia, which presumably occurred due to hemolysis (Table 1).

In general, wasp sting has no specific treatment, and wasp venom has no antidote. The primary principles of wasp sting management are (i) correcting hypovolemia to prevent renal ischemia; (ii) enhancing the clearance of heme proteins, toxins, or toxic wastes out of the systemic or renal circulation; and (iii) reducing the risk of direct venom toxicity, toxic waste, electrolyte imbalance, and heme protein in the kidney and other organs [2]. RRT is performed when the patient experiences AKI accompanied with oliguria or hyperkalemia, metabolic acidosis, or acute lung edema. HD, CRRT, and PE are the common extracorporeal treatment types, and the selection depends on disease severity [17]. Seven HD sessions were performed in the first case who suffered AKI without MODS, whereas CRRT was performed in the form of CVVHDF in the second case due to the presence of anuria and severe toxin effects, which was then continued with PE because of persistent hemolysis and severe toxin effects [9]. Remaining wasp toxins were suspected causing acute nephritis or kidney necrosis [17].

AKI following wasp stings is reversible in most cases. The duration of recovering kidney function back to its normal status in cases with AKI following wasp stings requiring dialysis is 3-6 weeks [9, 18-20]. Although the renal function is returned to normal, the kidney function should be continuously monitored for up to $4-8$ months because the condition may still progress into chronic kidney disease [21]. For both cases in this report, the monitoring was performed up to 4 years after the stings and showed that the kidney function remained normal. Long-term morbidity of wasp sting cases has not been confirmed; therefore, immediate diagnosis and treatment are essential to prevent renal damage [9].

Renal biopsy should be considered in AKI that occurs following wasp stings to diagnose acute interstitial nephritis, and steroid treatment should be started as illustrated in the second case to reduce interstitial fibrosis and prevent irreversible renal damage [5, 9, 21]. Acute tubular injury is the most common histopathological finding ( $>90 \%)$ in renal biopsies of patients with AKI due to wasp stings [6]. The biopsies in both cases showed acute tubular injury and acute interstitial nephritis without apparent abnormality in glomeruli, with slightly more tubular injury in Case 2 than in Case 1. However, interstitial inflammation and number of 


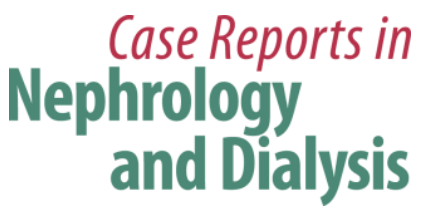

\begin{tabular}{l|l} 
Case Rep Nephrol Dial 2019;9:137-148 \\
\hline DOI: 10.1159/000504043 & $\begin{array}{l}\text { (c) 2019 The Author(s). Published by S. Karger AG, Basel } \\
\text { www.karger.com/cnd }\end{array}$ \\
\hline
\end{tabular}

Ambarsari et al.: Critical Cases of Pediatric AKI following Multiple Wasp Stings

eosinophils were greater in Case 1 . The follow-up biopsy result visually showed slightly better improvement in Case 2 with less fibrotic areas compared to Case 1, despite the fact that the event was presumably more severe (Fig. 2). Steroid treatment in Case 2 might be the reason for this phenomenon. Although the decision to repeat a renal biopsy in our cases should be based on the 24-h urinary protein excretion, we did not perform the laboratory test because both patients lived in remote areas. In the first case, we performed the second renal biopsy considering the significant interstitial inflammation shown in the first biopsy and his kidney function, which did not return to the normal range for up to 12 weeks after the event, while, in the second case, the decision to perform the second renal biopsy was due to persistent proteinuria despite normalized kidney function (Fig. 3c).

Other factors that extremely affect the prognosis of AKI due to wasp stings are the duration between the sting attack and the patient's arrival at the hospital as well as the medical team's experience in managing similar cases $[7,17]$. A multicenter, retrospective study in China concluded that patients who came late to the hospital $(>4 \mathrm{~h})$, had multiple wasp stings ( $\geq 20$ stings), and developed AKI could have good outcome when HD was performed immediately [7]. A case report in Bangladesh reported a case of AKI due to wasp stings that only received medical treatment on the 8th day. The patient had more severe loss of kidney function compared to the case that received treatment within $<3$ days after the stings [4]. Both cases in our report showed that although patients had delayed hospital admission to the tertiary hospital, fluid treatment had been administered for the first few days, which contributed to slow down the progressive development of AKI. Moreover, immediate dialysis when patients arrived at the tertiary hospital and selection of an accurate treatment modality successfully eliminated wasp toxins and therefore promoted the achievement of complete recovery of kidney function.

In children who had multiple wasp stings, laboratory workup should be performed immediately after the stings, followed by daily monitoring on progressive symptoms. The monitoring is especially carried out to evaluate organ and system functions that usually result in complications following wasp stings such as kidney, liver, hematopoietic system, coagulation function, and other rarely involved organs such as the pancreas and eyes. Although kidney dysfunction usually gradually occurs within the first few days with a high mortality rate, IV fluid administration may slow down the progression of renal damage. Steroid treatment seems beneficial to alleviate interstitial fibrosis. Immediate extracorporeal treatment with the right choice of treatment modality can promote kidney function recovery and good prognosis to prevent chronic kidney disease development.

\section{Acknowledgements}

We would like to thank Prof. Taralan Tambunan; Sudung Oloan Pardede, MD, PhD; Eka Laksmi Hidayati, MD; and Henny Adriani Puspitasari, MD, for their care of the patients at the Department of Child Health. We kindly acknowledge pediatric dialysis nurses of CMH, Yetti Marlina, Mustaqimah, Dorkasturi Sitompul, Meldahania, Ani Suryani, Emma Meida Ekawati, and Resti Fitria Pramandani for their service in the dialysis unit and in maintaining database, and former pediatric dialysis nurse of $\mathrm{CMH}$, Andri Nurrohman, for carefully performing the extracorporeal treatment sessions, particularly in the second case. We would also like to thank 

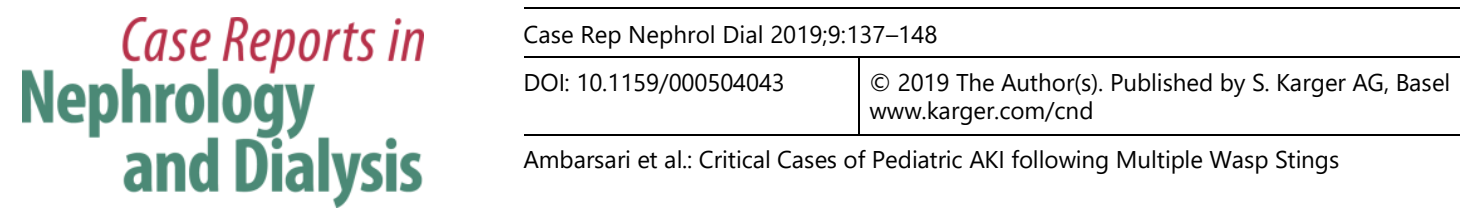

Elysabeth Muliawan, MD, for her editing service on the English version of the manuscript and ENAGO (http://www.enago.com) for the careful reading and editing of this report.

\section{Statement of Ethics}

The research was conducted in ethical accordance with the World Medical Association Declaration of Helsinki. Written informed consent was obtained from the caregivers for the publication of this case report and any accompanying images. A copy of the written consent is available for review from the Editor of this journal.

\section{Disclosure Statement}

The authors declare that they have no competing interests.

\section{Funding Sources}

The authors did not receive any funding.

\section{Author Contributions}

C.G.A. and R.M.S. performed the literature search, data collection, data analysis, and data interpretation, and wrote the first draft of the manuscript. M.S. performed the data collection and data analysis, critically reviewed the manuscript, and approved the final version. P.P.T. critically reviewed the manuscript. All authors read and approved the final version of the manuscript.

\section{References}

1 Ryakitimbo A, Kennedy M, Shao E, Itana ME, Mbwasi R, Kinabo G, et al. Acute Kidney Injury in a Tanzanian Boy following Multiple Bee Stings in Resource-Limited Setting: A Case Report. Oxf Med Case Reports. 2018 Oct;2018(10):omy070.

2 Dongol Y, Shrestha RK, Aryal G, Lakkappa BD. Hymenoptera Stings and the Acute Kidney Injury.EMJ Nephl. 2013 Jul;10:68-75.

3 Thiruventhiran T, Goh BL, Leong CL, Cheah PL, Looi LM, Tan SY. Acute renal failure following multiple wasp stings. Nephrol Dial Transplant. 1999 Jan;14(1):214-7.

4 Tahura S, Hanif M. Advances in Clinical Toxicology Acute Kidney Injury in Children following Multiple Wasp Stings and its Immediate Outcome. Adv Clin Toxicol. 2018;3(1):000124.

5 Atmaram VP, Mathew A, Kurian G, Unni VN. Acute Renal Failure Following Multiple Wasp Stings. Indian J Nephrol. 2005 Jan;15(1):30-2.

6 Vikrant S, Parashar A. Acute kidney injury due to multiple Hymenoptera stings-a clinicopathological study. Clin Kidney J. 2017 Aug;10(4):532-8.

7 Xie C, Xu S, Ding F, Xie M, Lv J, Yao J, et al. Clinical features of severe wasp sting patients with dominantly toxic reaction: analysis of 1091 cases. PLoS One. 2013 Dec;8(12):e83164. 


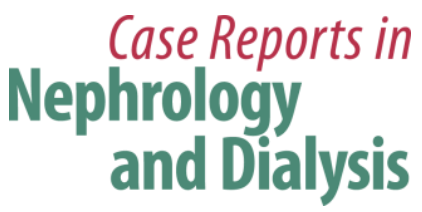

\begin{tabular}{l|l}
\hline Case Rep Nephrol Dial 2019;9:137-148 \\
\hline DOI: 10.1159/000504043 & $\begin{array}{l}\text { (c) 2019 The Author(s). Published by S. Karger AG, Basel } \\
\text { www.karger.com/cnd }\end{array}$ \\
\hline
\end{tabular}

8 Chowdhury FR, Bari MS, Shafi AM, Mumith A, Hossain ME, Chowdhury S, et al. Acute Kidney Injury following Rhabdomyolysis due to Multiple Wasp Stings (Vespa affinis). Asia Pac J Med Toxicol. 2014 Mar;408(1):20135.

9 Dhakal AK, Basnet NB, Shrestha D. Acute Kidney Injury due to Multiple Wasp Stings in an Eight-Year-Old Child. J Kathmandu Med Coll. 2013 Sep;2(3):145-7.

10 George P, Pawar B, Calton N, Mathew P. Wasp sting: an unusual fatal outcome. Saudi J Kidney Dis Transpl. 2008 Nov;19(6):969-72.

11 Sigdel MR, Raut KB. Wasp bite in a referral hospital in Nepal. J Nepal Health Res Counc. 2013 Sep;11(25):244-50.

12 Ghosh JB, Roy M, Bala AK. Delayed onset interstitial nephritis following multiple wasp stings. Indian J Nephrol. 2009 Apr;19(2):71-3.

13 Yang SH, Song YH, Kim TH, Kim SB, Han SY, Kim HS, et al. Acute Pancreatitis and Rhabdomyolysis with Acute Kidney Injury following Multiple Wasp Stings. Case Rep Nephrol. 2017;2017:8596981.

14 Maltzman JS, Lee AG, Miller NR. Optic neuropathy occurring after bee and wasp sting. Ophthalmology. 2000 Jan;107(1):193-5.

15 Sheth HG, Sullivan TJ. Optic neuropathy and orbital inflammatory mass after wasp stings. J R Soc Med. 2004 Sep;97(9):436-7.

16 Lai P, Yang J, Cui H, Xie H. Prognosis of corneal wasp sting: case report and review of the literature. Cutan Ocul Toxicol. 2011 Dec;30(4):325-7.

17 Zhang L, Yang Y, Tang Y, Zhao Y, Cao Y, Su B, et al. Recovery from AKI following Multiple Wasp Stings : A Case Series. Clin J Am Soc Nephrol. 2013 Nov;81(11):1850-6.

18 Vetter RS, Visscher PK, Camazine S. Mass Envenomations by Honey Bees and Wasps. West J Med. 1999 Apr;170(4):223-7.

19 Zhang R, Meleg-Smith S, Batuman V. Acute tubulointerstitial nephritis after wasp stings. Am J Kidney Dis. 2001 Dec;38(6):E33.

20 Anwar S, Hossain N, Rozana FK, Sumon SM. Acute Kidney Injury Following Wasp Stings - A Case Report and Literature Review. Bangladesh J Child Health. 2018 Jul;42(2):98-101.

21 Dhanapriya J, Dineshkumar T, Sakthirajan R, Shankar P, Gopalakrishnan N, Balasubramaniyan T. Wasp stinginduced acute kidney injury. Clin Kidney J. 2016 Apr;9(2):201-4.
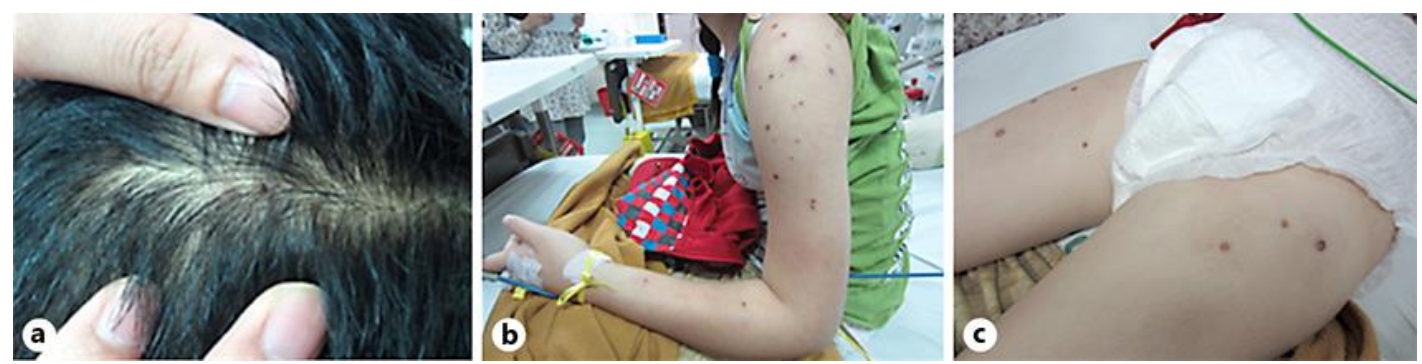

Fig. 1. a Case 1: wasp sting marks over his scalp. b Case 2: wasp sting marks over her left upper arm. c Case 2: wasp sting marks over her upper extremities. 


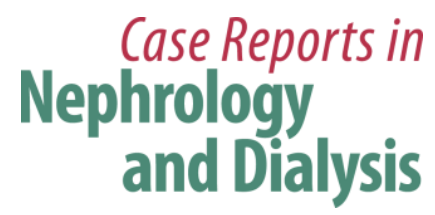

Case Rep Nephrol Dial 2019;9:137-148

DOI: $10.1159 / 000504043$

(C) 2019 The Author(s). Published by S. Karger AG, Basel www.karger.com/cnd

Ambarsari et al.: Critical Cases of Pediatric AKI following Multiple Wasp Stings
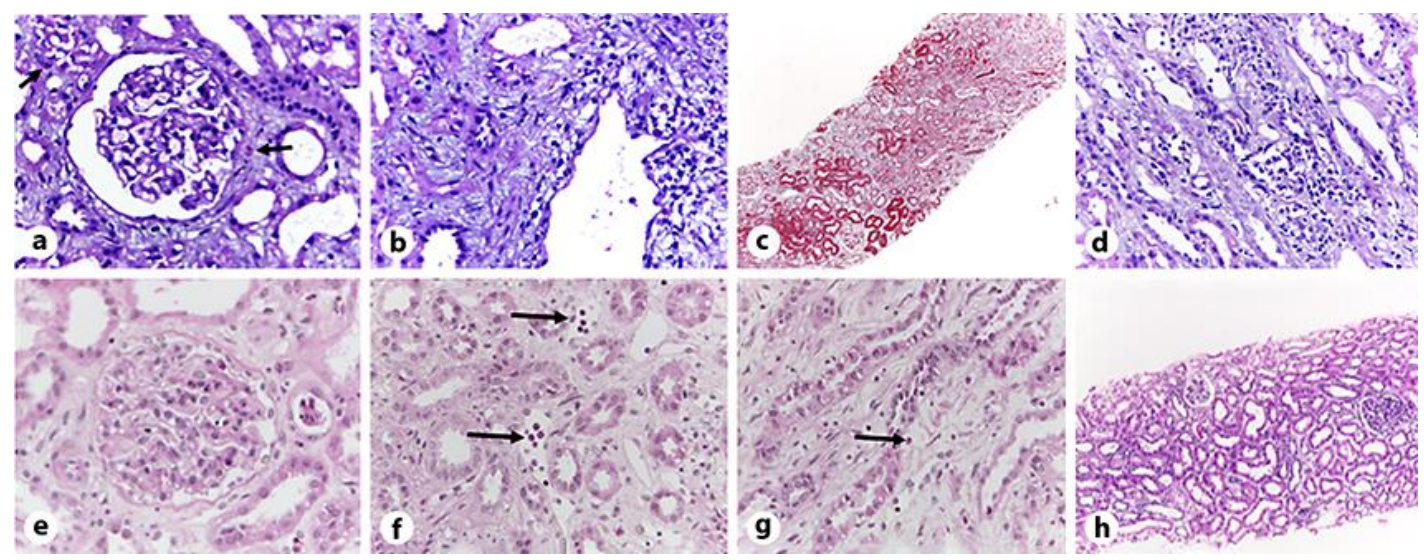

Fig. 2. a, b. Case 1: renal biopsy at the 15 th day following the wasp stings, showing 36 viable normocellular glomeruli without any sclerosis. The proximal tubules showed loss of brush borders and mild epithelial detachment. A few tubules with protein and cellular casts were also detected. The interstitium was edematous with moderate infiltration of mononuclear cells and eosinophils, especially in the medulla. Immune deposits were not found in immunofluorescence examination. a Glomerulus with urinary space widening. A few eosinophils were detected. HE. $\times 400$. b Inflammatory cell infiltration in the cortical interstitium. Reactive tubular epithelial cells were also detected. HE. $\times 400$. c, $d$ Case 1 : second biopsy 12 weeks after the wasp stings showed slight improvement; however, chronic features were already found. The glomerulus no longer showed urinary space widening. No glomerulosclerosis was noted. Focal fibrosis was observed with some tubules, showing wrinkled basement membrane, simplification, and thyroidization. A few cellular casts were still found. Tubular epithelial shedding was not a prominent feature; nevertheless, it could still be observed in very few tubules. The interstitial tissue was less edematous but showed more fibrotic areas. Diffuse infiltration of inflammatory cells were also detected throughout the cortex and medulla to a lesser degree. Eosinophils were also found. c Focal area of fibrosis with preservation of some tubules (Masson trichrome, $\times 400$ ). $\mathbf{d}$ Patchy inflammation could still be identified. HE. $\times 400$. e-g Case 2: renal biopsy at the 19th day after the wasp stings showed features similar to those in Case 1. A sufficient number of viable glomeruli was observed, and no immune-related abnormality was found. Some glomeruli (3-4 glomeruli) also showed urinary space widening. Most tubules seemed dilated, and a few proximal tubules showed loss of the brush border accompanied with epithelial detachment. More cellular casts were found compared to the first biopsy of Case 1 . The interstitial tissue was edematous with only mild inflammatory cell infiltration with a few eosinophils, and a few neutrophils were also found. No immune deposit was identified during the immunofluorescence examination. e Increased number of neutrophils in the glomerulus, reactive podocytes, and cellular casts in the tubular lumen. HE. $\times 400$. $f$ Increased number of neutrophils within the lumen of peritubular capillaries. HE. $\times 400$. g Less inflammation was also noted. Eosinophils could be found. HE. $\times 400$. $h$ Case 2 : second biopsy was performed at the 10 th week after the wasp stings, which showed improved morphological features and no glomerulosclerosis. The tubules were not as dilated as those observed in the first biopsy. A few proximal tubules still showed loss of the brush border and epithelial detachment. Although some tubules showed simplification, tubular atrophy was observed to be extremely minimal. The interstitium only showed very mild fibrosis. The number of inflammatory cells was also reduced. $\mathbf{h}$ The results of the second kidney biopsy in Case 2, showing less fibrotic areas compared to the second kidney biopsy in Case 1 . Thyroidization could be observed with tubular epithelial detachment. HE. $\times 100$. 


\section{Case Reports in Nephrology and Dialysis}

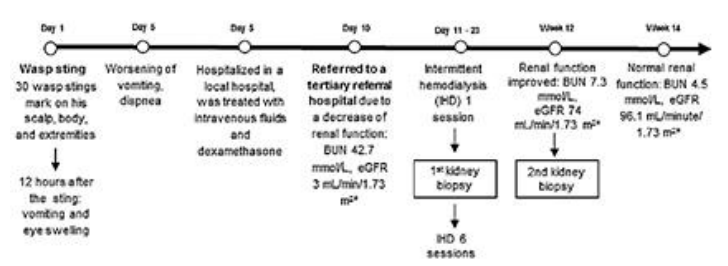

a
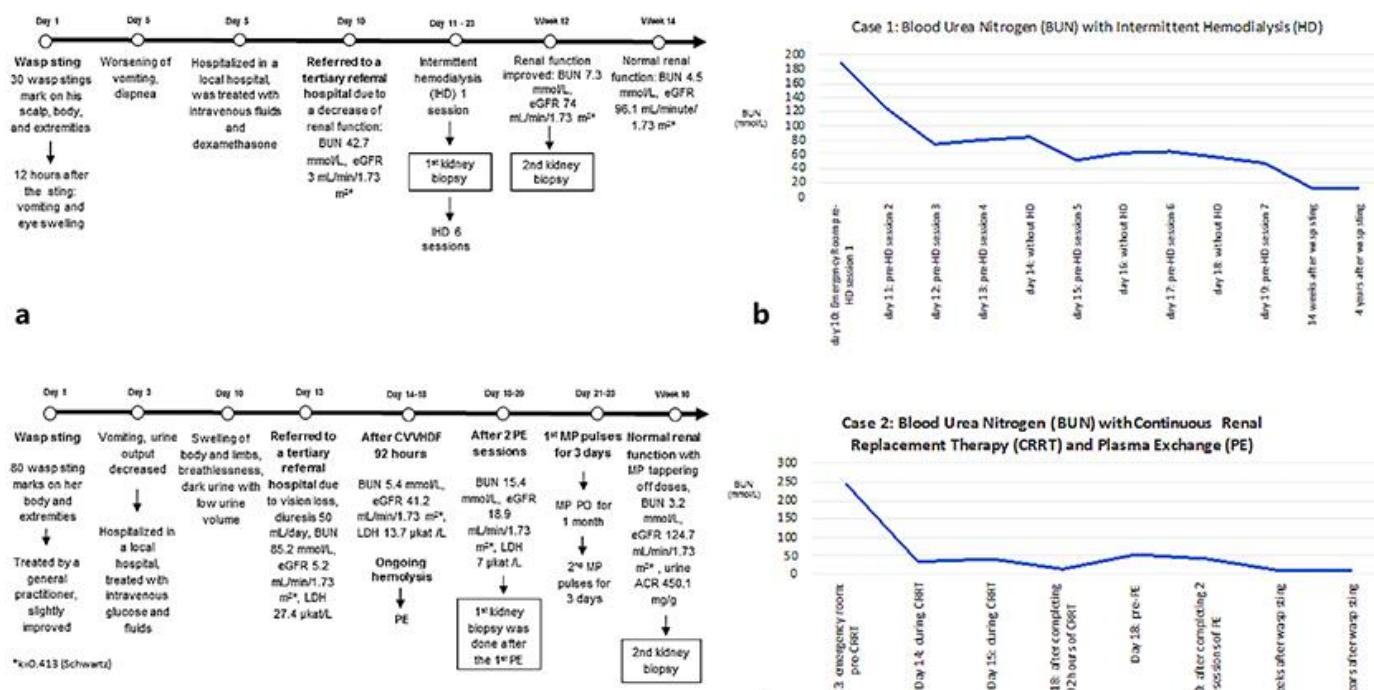

C

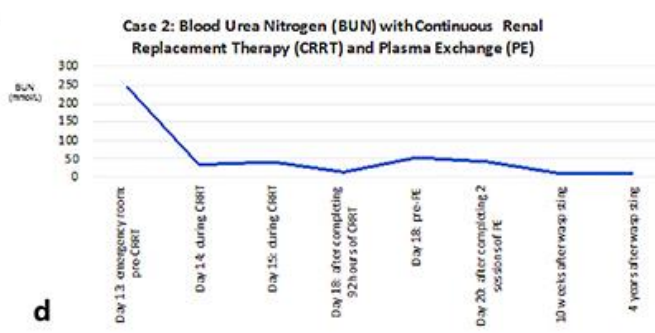

Fig. 3. a Case 1: timeline. b Case 1: BUN with intermittent hemodialysis. c Case 2: timeline. d Case 2: BUN with continuous RRT and PE. 


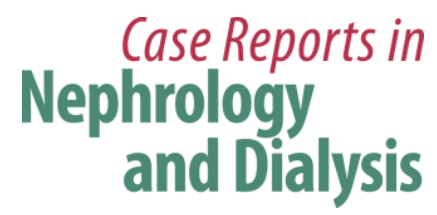

\begin{tabular}{l|l}
\hline Case Rep Nephrol Dial 2019;9:137-148 \\
\hline DOI: 10.1159/000504043 & $\begin{array}{l}\text { @ } 2019 \text { The Author(s). Published by S. Karger AG, Basel } \\
\text { www.karger.com/cnd }\end{array}$ \\
\hline
\end{tabular}

Table 1. Laboratory investigations on admission to $\mathrm{CMH}$

\begin{tabular}{|c|c|c|c|}
\hline Variable & Normal range & Case 1 & Case 2 \\
\hline Hemoglobin, g/L & $125-161$ & 123 & 80.1 \\
\hline Platelets, $\times 10^{9} / \mathrm{L}$ & $150-400$ & 540 & 460 \\
\hline Leukocytes, $\times 10^{9} / \mathrm{L}$ & $4-10.5$ & 23.1 & 30 \\
\hline $\mathrm{ESR}, \mathrm{mm} / \mathrm{h}$ & $0-20$ & 83 & 72 \\
\hline Peripheral blood smear & & $\begin{array}{l}\text { normocytic } \\
\text { normochromic, burr cell }\end{array}$ & $\begin{array}{l}\text { microcytic, hypochromic, an- } \\
\text { isopoikilocytosis, pencil cell }\end{array}$ \\
\hline Absolute reticulocytes, $\times 10^{9} / \mathrm{L}$ & $24-95$ & 26 & 34 \\
\hline BUN, mmol/L & $2.5-7.14$ & 67.26 & 85.16 \\
\hline Creatinine, $\mu \mathrm{mol} / \mathrm{L}$ & $53-108$ & $2,193.4$ & $1,068.5$ \\
\hline $\mathrm{eGFR}, \mathrm{mL} / \mathrm{min} / 1.73 \mathrm{~m}^{2^{*}}$ & $94-142$ & 4.6 & 5.16 \\
\hline Sodium, $\mathrm{mmol} / \mathrm{L}$ & $132-147$ & 137 & 121 \\
\hline Potassium, mmol/L & $3.3-5.4$ & 6.8 & 6 \\
\hline Chloride, mmol/L & $94-111$ & 97 & 89 \\
\hline Bicarbonate, $\mathrm{mmol} / \mathrm{L}$ & $21-25$ & 10.8 & 10.7 \\
\hline Calcium ion, mmol/L & $1.01-1.31$ & 1.04 & 0.72 \\
\hline Phosphate, mmol/L & $1.13-1.29$ & 2 & 2.36 \\
\hline Magnesium, mmol/dL & $0.7-1.05$ & 1.04 & 0.92 \\
\hline Urid acid, $\mu \mathrm{mol} / \mathrm{L}$ & $<362.86$ & 591.3 & 743.6 \\
\hline $\mathrm{LDH}, \mu \mathrm{kat} / \mathrm{L}$ & $<5.01$ & 17.87 & 27.44 \\
\hline Albumin, g/L & $38-54$ & 36.2 & 34.8 \\
\hline AST, $\mu \mathrm{kat} / \mathrm{L}$ & $<0.45$ & 0.22 & 1.4 \\
\hline ALT, $\mu \mathrm{kat} / \mathrm{L}$ & $<0.38$ & 0.45 & 3.17 \\
\hline $\mathrm{CK}, \mu \mathrm{kat} / \mathrm{L}$ & $<2.05$ & 1.72 & 4.06 \\
\hline CK-MB, $\mu$ kat/L & $<0.4$ & 0.27 & 0.44 \\
\hline Blood myoglobin (qualitative) & negative & negative & negative \\
\hline Troponin T, $\mu \mathrm{g} / \mathrm{L}$ & $<14$ & 104 & negative (qualitative) \\
\hline GGT, $\mu \mathrm{kat} / \mathrm{L}$ & $<0.55$ & 0.42 & 0.58 \\
\hline ALP, $\mu$ kat $/ \mathrm{L}$ & $<5.28$ & 1.67 & 1.44 \\
\hline Triglycerides, mmol/L & $<1.7$ & 0.7 & 2.37 \\
\hline Total cholesterol, $\mathrm{mmol} / \mathrm{L}$ & $2.8-5.3$ & 3.5 & 3.7 \\
\hline $\mathrm{HDL}, \mathrm{mmol} / \mathrm{L}$ & $\geq 1.0345$ & 0.6 & 0.46 \\
\hline $\mathrm{LDL}, \mathrm{mmol} / \mathrm{L}$ & $\leq 3.4$ & 2.4 & 2.2 \\
\hline Amylase, $\mu \mathrm{kat} / \mathrm{L}$ & $<0.65$ & 0.75 & 3.37 \\
\hline Lipase, $\mu$ kat/L & $<0.77$ & 0.68 & 5.96 \\
\hline $\mathrm{PT}, \mathrm{s}$ & $9.8-12.6$ & 12.5 & 11.8 \\
\hline APTT, s & $31.0-47.0$ & 36.3 & 41.6 \\
\hline Fibrinogen, g/L & $1.36-3.84$ & 3.59 & 2.36 \\
\hline IgE, mg/L & $<0.48$ & 1.58 & 0.33 \\
\hline \multicolumn{4}{|l|}{ Urinalysis } \\
\hline Color & yellow & dark yellow & dark yellow \\
\hline $\mathrm{pH}$ & $4.5-8$ & 6 & 7.5 \\
\hline Specific gravity & $1.005-1.030$ & 1.010 & 1.010 \\
\hline Protein & negative & $1+$ & $2+$ \\
\hline Blood/hemoglobin & negative & $2+$ & $3+$ \\
\hline Leukocytes, hpf & $0-5$ & $2-3$ & $8-9$ \\
\hline ESR, hpf & $0-2$ & $15-18$ & $24-25$ \\
\hline Urine ACR, mg/g & $<30$ & 327 & $1,536.9$ \\
\hline
\end{tabular}

ESR, erythrocyte sedimentation rate; BUN, blood urea nitrogen; eGFR, estimated glomerular filtration rate; LDH, lactate dehydrogenase; AST, aspartate aminotransferase; ALT, alanine aminotransferase; CK, creatine kinase; CK-MB, creatine kinase muscle/brain; GGT, gamma glutamyl transferase; ALP, alkaline phosphatase; HDL, high-density lipoprotein; LDL, low-density lipoprotein; PT, prothrombin time; APTT, activated partial thromboplastin time; IgE, immunoglobulin E; urine ACR, urine albumin/creatinine ratio. ${ }^{*} \mathrm{k}=0.413$ (Schwartz). 

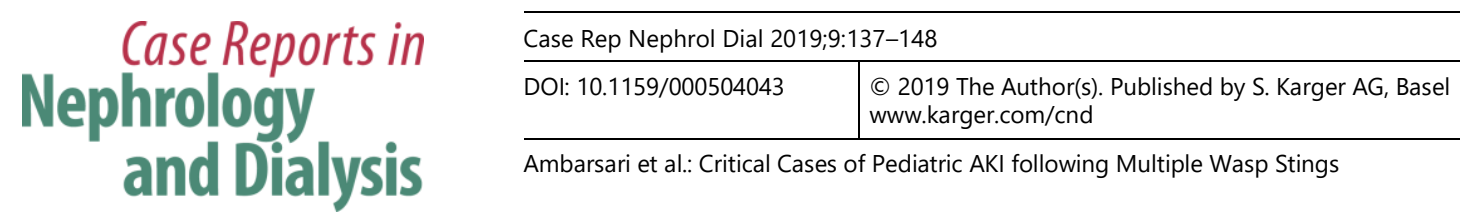

Ambarsari et al.: Critical Cases of Pediatric AKI following Multiple Wasp Stings

Table 2. Case 2: summary of the clinical course (day $0=$ event of the wasp stings)

\begin{tabular}{|c|c|c|c|c|c|c|c|c|}
\hline Variables & $\begin{array}{l}\text { Normal } \\
\text { range }\end{array}$ & $\begin{array}{l}\text { Day } 13 \\
\text { on } \\
\text { admission } \\
\text { to } \mathrm{CMH}\end{array}$ & $\begin{array}{l}\text { Day } 15 \\
\text { after } 92 \mathrm{~h} \\
\text { of CRRT }\end{array}$ & $\begin{array}{l}\text { Day } 18 \\
\text { after } \\
1 \text { st PE }\end{array}$ & $\begin{array}{l}\text { Day } 19 \\
\text { before } \\
\text { 2nd PE }\end{array}$ & $\begin{array}{l}\text { Day } 20 \\
\text { after } \\
\text { 2nd PE }\end{array}$ & $\begin{array}{l}\text { Week } 7 \\
\text { while on } \\
\text { MPPO } \\
32 \text { mg daily }\end{array}$ & $\begin{array}{l}\text { Week } 10 \\
\text { while on MP } \\
\text { PO } 16 \mathrm{mg} \\
\text { alternate doses }\end{array}$ \\
\hline Hemoglobin, g/L & $125-161$ & 80.1 & 125 & 123 & 99 & 88.3 & 133 & \\
\hline Platelets, $\times 10^{9} / \mu \mathrm{L}$ & $150-400$ & 460 & 219 & 180 & 186 & 139 & 284 & \\
\hline LDH, $\mu \mathrm{kat} / \mathrm{L}$ & $<5.01$ & 27.44 & 13.71 & 8.45 & 8.65 & 6.95 & 9.07 & \\
\hline CK, $\mu$ kat/L & $<2.05$ & 4.06 & & 2.27 & 2.97 & & 0.35 & \\
\hline CK-MB, $\mu \mathrm{kat} / \mathrm{L}$ & $<0.4$ & 0.44 & & 0.29 & 0.17 & & 0.31 & \\
\hline AST, $\mu$ kat/L & $<0.45$ & 1.4 & & 0.93 & & 0.45 & & 0.3 \\
\hline $\mathrm{ALT}, \mu \mathrm{kat} / \mathrm{L}$ & $<0.38$ & 3.17 & & 2 & & 0.83 & & 0.32 \\
\hline BUN, mmol/L & $2.5-7.14$ & 85.1 & 5.4 & & 18.6 & 15.4 & 11.1 & \\
\hline Creatinine, $\mu \mathrm{mol} / \mathrm{L}$ & $53-108$ & $1,068.5$ & 133.9 & & 357.4 & 291.9 & 79.5 & \\
\hline $\mathrm{eGFR}, \mathrm{mL} / \mathrm{min} / 1.73 \mathrm{~m}^{2^{*}}$ & $94-142$ & 5.16 & 41.2 & & 15.4 & 18.9 & 124.7 & \\
\hline Proteinuria & negative & $2+$ & & $1+$ & & & & negative \\
\hline Urine ACR, mg/g & $<30$ & & & 871.3 & & 400 & 596.1 & 17.6 \\
\hline Amylase, $\mu$ kat/L & $<0.65$ & 3.37 & 0.82 & & & 0.75 & 0.68 & \\
\hline Lipase, $\mu \mathrm{kat} / \mathrm{L}$ & $<0.77$ & 5.96 & 1.69 & & & 0.95 & 0.67 & \\
\hline
\end{tabular}

CMH, Cipto Mangunkusumo Hospital; CRRT, continuous renal replacement therapy; PE, plasma exchange; MPPO, methylprednisolone per oral; LDH, lactate dehydrogenase; CK, creatine kinase; CK-MB, creatine kinase muscle/brain; AST, aspartate aminotransferase; ALT, alanine aminotransferase; BUN, blood urea nitrogen; eGFR, estimated glomerular filtration rate; urine ACR, urine albumin/creatinine ratio. * $\mathrm{k}=$ 0.413 (Schwartz). 